\title{
"The Job Has Become Advocating for the Job": Threats to Funding Dramatically Influence Program Outcomes
}

\author{
Anna McCullough, MSW, MSPH', Leah M. Ranney, PhD', \\ Daniel J. Simons, MA', and Adam O. Goldstein, MD, MPH'
}

\begin{abstract}
As public health funding is increasingly threatened, a better understanding is needed about how periods of funding uncertainty impact program staff, activities, and outcomes. In North Carolina, 2 years of uncertainty and threats of funding cuts for a statewide youth tobacco prevention initiative contributed to reduced grantee morale and confidence about achieving program goals, displaced focus from core program activities, and caused premature loss of personnel, resulting in substantially reduced program activities and outcomes. The range of negative impacts of funding uncertainty and threats highlights the need for programs to create an infrastructure to support ongoing sustainability planning and activities.
\end{abstract}

\section{Keywords}

program sustainability, program funding, advocacy, tobacco control

\section{Introduction}

In 2001, North Carolina established the Health and Wellness Trust Fund (HWTF), with $25 \%$ of North Carolina's Master Settlement funding, to reduce and prevent youth and young adult tobacco use. ${ }^{1}$ In 2003, HWTF launched a statewide Teen Tobacco Use Prevention and Cessation Initiative (Teen Initiative) that engaged youth in community and school-based programs focused on education, prevention, and policy and environmental change. Coupled with a statewide media campaign, the Teen Initiative contributed to dramatic declines and historically low youth smoking rates. ${ }^{2}$ Despite documented success, in May 2011, the North Carolina General Assembly abolished the HWTF, effective June 30, 2011; 1 year of nonrecurring funds for youth tobacco prevention shifted to the North Carolina Department of Health and Human Services (DHHS) as part of the 2011 to 2013 biannual state budget act.

Approximately 3 months passed between the initial threat of funding cuts in 2011 and the decision to abolish the HWTF, creating a period of sustained uncertainty for HWTF program grantees. The 2-year state budget adopted in 2011 shifted funds to DHHS for only fiscal year (FY) 2012 (July 1, 2011, to June 30,2012 ), sustaining youth tobacco prevention grantee efforts for that year with the possibility that an additional year's funding would be provided in the annual budget adjustment process conducted in 2012. This possibility created an atmosphere of continued uncertainty for program staff and grantees through most of FY 2012. Ultimately, the FY 2013 state budget allocated drastically reduced tobacco cessation and prevention funding, essentially dismantling the statewide youth prevention infrastructure built by HWTF and sustained by DHHS through FY 2012.

Eliminating state tobacco control programs is associated with reductions in key program outcomes, including reduced awareness of countermarketing campaigns and increased adolescent susceptibility and use. ${ }^{3-5}$ However, little is known about how threats of funding cuts and periods of uncertainty about the future of an established program, such as those experienced in North Carolina, may impact public health programs' abilities to implement core activities and achieve program goals. As state and federal funding for public health programs is increasingly uncertain, improved understanding of how such periods of uncertainty may impact programs can inform improved program sustainability planning. We present findings from a process and outcome evaluation of the North Carolina youth tobacco prevention programs over a 3-year period in which program funding was secure, threatened, transferred to another entity, and ultimately drastically reduced.

\footnotetext{
' Department of Family Medicine, School of Medicine, University of North Carolina at Chapel Hill, Chapel Hill, NC, USA
}

\section{Corresponding Author:}

Anna McCullough, Department of Family Medicine, School of Medicine, University of North Carolina at Chapel Hill, 590 Manning Drive, CB \#7595, Chapel Hill, NC 27599, USA.

Email: annamc@unc.edu 


\section{Methods}

Independent evaluation data for FY 2010 to 2012 are presented. Evaluation data collected from program grantees via a webbased reporting tool and surveys included quantitative process and outcome measures related to programmatic foci (eg, youth empowerment, youth access, and smoke-free policy adoption) and qualitative data (eg, descriptions of youth empowerment activities). In April 2012, 2 focus groups were conducted with a total of 15 grantees to explore experiences related to communicating with policy makers about the program. Focus groups were audio-recorded and transcribed; transcripts were loaded into MAXQDA 10 (VERBI Software, Marburg, Germany) and analyzed using a deductive coding approach.

\section{Results}

Overall programmatic activity declined $15 \%$ in the last quarter of FY 2011 compared to the last quarter of FY 2010, with substantial decreases in key program areas including youth empowerment and point-of-sale efforts as HWTF funding was under threat. Youth engagement (a primary program focus) declined 13\% between January 2011 and January 2012 amid continued uncertainty about program funding. Grantees reported decreased confidence in achieving programmatic goals in the second half of both FY 2011 and FY 2012, as funding cuts were threatened or impending. Several grantees left their positions in FY 2012, resulting in a premature end to program activities and incomplete final evaluation reporting by more than $25 \%$ of grantees.

Focus group results illustrated funding threats' negative impact on grantees' morale and perceived ability to effectively implement programs. As funding cuts were threatened, many grantees reported a perceived need to shift their time and energy to educating policy makers in an effort to sustain program funding to the detriment of core program activities and youth engagement.

This past year...my action plan hasn't even been looked at because everything that we had intended to do was put on hold because of reaching out to elected officials and trying to get them to save the program.

I really feel like my job has shifted from being working with youth educating other youth about tobacco prevention to really fighting for our job.

Grantees reported significant frustration with this shift in focus and with perceived barriers to effectively communicating with policy makers. Many grantees described a significant barrier related to state policies prohibiting the use of state resources for lobbying activities, describing feeling stymied by the "fine line" between educating and lobbying.

It's hard as a county employee to do some of the outreach... You have to be very careful what you do on work time, what you send out, how you send it out, to not cross that line between advocacy and lobbying.
Many grantees described frustration that their efforts to reach policy makers often went unanswered, saying that the lack of response made them question their communication efforts and made it difficult to keep youth engaged in efforts to communicate with policy makers.

We send stuff out, but we don't get feedback back. So, we don't know what's working and what's not. I mean, I send e-mail, I send letters, I send them copies of press releases, but I'm not hearing back from them...

Some grantees highlighted a lack of guidance at the program level as a barrier to effective communication with policy makers; grantees who had been with the program for several years focused on inconsistent emphasis on policy maker education over the years, whereas newer grantees described relying on guidance from external advocacy groups in the absence of program-level guidance.

Until funding was in jeopardy, I never ... ever considered my job getting in touch with legislators ... my job was working with youth and teen tobacco prevention. But, I feel like the job has become advocating for the job.

I think that Health and Wellness could have done more [to] encourage us to do the things within our parameters to contact our legislators or... We probably should have been doing that the whole time so that they always knew how important this program is.

\section{Discussion}

Our findings demonstrate that even the threat of funding loss, well in advance of cuts being implemented, can adversely impact public health programs. In North Carolina, 2 years of uncertainty about future funding for the statewide youth tobacco prevention program reduced grantee morale and confidence about achieving programmatic goals, displaced focus from programmatic activities to communicating with policy makers about the need for continued funding, and caused premature loss of personnel. Taken together, these factors contributed to substantially reduced program activities and outcomes in the statewide program's final 2 years.

Further, grantees encountered a number of barriers to effective communication with policy makers at a time when program funding was being targeted. Uncertainty about the effectiveness of communication strategies and frustration over lack of responses from policy makers were identified as a significant barrier by many grantees. Focus group findings also highlighted important structural barriers, including barriers related to restrictions on using paid work time to engage in advocacy and a perceived lack of consistent proactive guidance from program leaders about sustainability-related education and advocacy efforts with legislators.

Grantees expressed difficulty with balancing program sustainability efforts and perceived "core" program activities during times of funding uncertainty. Ensuring that efforts related 
to sustainability, including communication with policy makers, are consistently emphasized throughout a program's lifecycle may support program staff in viewing sustainability work as an integral part of achieving overall program goals. When proactively communicating with policy makers, emerging evidence suggests that engaging constituents in direct communication with legislators, framing the benefits of public health programs in ways that align with policy makers' expressed values, and emphasizing the economic value of programs may be valuable communication strategies. $^{6}$

Since program funding was ultimately drastically reduced, resulting in elimination of the statewide youth prevention infrastructure, it seems unlikely that grantee advocacy efforts measurably impacted the final legislative decision. There is some evidence that appropriate relationship development between program staff or partners (eg, evaluators) and policy makers, along with proactive, consistent communication regarding program outcomes, may help increase policy maker support for programs. ${ }^{7,8}$ However, it is important to note that threats to North

\section{SO WHAT?}

What is already known on this topic?

Despite documented successes in outcomes, public health funding for tobacco control programs is increasingly threatened across the country. In 201 I, the North Carolina General Assembly abolished the Health and Wellness Trust Fund funded by the Master Settlement Agreement, despite documented historic reductions of youth tobacco use in the state as a result of the Trust Fund's tobacco programs.

What does this article add?

The study findings show that even threats of funding loss that occurred long before the program ended, adversely impacted public health programs. Uncertainty about future funding impacted morale, reduced confidence in achieving program goals, displaced focus from program activities to program sustainability, and caused premature loss of personnel; process changes that led to decreased program outcomes.

What are the implications for health promotion practice or research?

Threats to program funding, even in the absence of funding cuts, may adversely impact program outcomes. There is a need for public health programs to create an infrastructure that supports effective, consistent efforts to ensure not only program evaluation but also program sustainability once positive outcomes are achieved. Building sustainability efforts into the framework of public health programs provides freedom from unforeseen funding threats that may eliminate otherwise successful programs.
Carolina's youth tobacco prevention program coincided with a significant political shift in the North Carolina General Assembly, as both the house and senate became Republican majority for the first time in more than 100 years. Given the well-documented history of tobacco industry influence in North Carolina politics, ${ }^{9,10}$ it seems likely that industry lobbying mitigated tobacco control advocacy efforts as the new legislative leadership became increasingly hostile toward tobacco control efforts.

Taken together, the negative impacts of funding threats on program outcomes, multilevel barriers to communicating with policy makers, and a perceived disconnect between sustainability efforts and core program goals experienced by youth tobacco prevention programs in North Carolina highlight a need for public health programs to create an infrastructure that supports effective, consistent efforts to ensure ongoing program funding and impact. Such efforts may be supported by implementing a sustainability framework designed to help programs conceptualize their capacity for sustainability and identify areas which they can incorporate sustainability efforts in their day-to-day work, ${ }^{11}$ taking into account relevant political climates and competing lobbying interests. As public health funding at the federal and state levels is continually under threat, deliberate and strategic sustainability planning is increasingly critical.

\section{Declaration of Conflicting Interests}

The author(s) declared no potential conflicts of interest with respect to the research, authorship, and/or publication of this article.

\section{Funding}

The author(s) received no financial support for the research, authorship, and/or publication of this article.

\section{References}

1. Davis JW. The Health and Wellness Trust Fund Commission. $N C$ Med J. 2002;63(3):165-166.

2. North Carolina Department of Health and Human Services. Teen smoking rates drop to historic low. 2012. NC Department of Health and Human Services Web site. http://www2.ncdhhs.gov/ pressrel/2012/2012-05-17_teen_smoking_drops.htm. Accessed May 18, 2016. Updated 2012.

3. Davis KC, Crankshaw E, Farrelly MC, Niederdeppe J, Watson K. The impact of state tobacco control program funding cuts on teens' exposure to tobacco control interventions: evidence from Florida. Am J Health Promot. 2011;25(3):176-185.

4. Pizacani BA, Dent CW, Maher JE, et al. Smoking patterns in Oregon youth: effects of funding and defunding of a comprehensive state tobacco control program. J Adolesc Health. 2009;44(3):229-236.

5. Sly DF, Arheart K, Dietz N, et al. The outcome consequences of defunding the Minnesota youth tobacco-use prevention program. Prev Med. 2005;41(2):503-510.

6. Schmidt AM, Ranney LM, Goldstein AO. Communicating program outcomes to encourage policymaker support for evidencebased state tobacco control. Int J Environ Res Public Health. 2014;11(12):12562-12574.

7. Dodson EA, Stamatakis KA, Chalifour S, Haire-Joshu D, McBride T, Brownson RC. State legislators' work on public 
health-related issues: what influences priorities? J Public Health Manag Pract. 2013;19(1):25-29.

8. Nelson DE, Reynolds JH, Luke DA, et al. Successfully maintaining program funding during trying times: lessons from tobacco control programs in five states. $J$ Public Health Manag Pract. 2007;13(6):612-620.

9. Goldstein AO, Bearman NS. State tobacco lobbyists and organizations in the united states: crossed lines. Am J Public Health. 1996;86(8):1137-1142.
10. Washington M, Barnes RL, Glantz S. Chipping away at tobacco traditions in tobacco country: tobacco industry political influence and tobacco policy making in North Carolina 1969-2011. Center for Tobacco Control Research and Education. 2011. Web site. http://escholarship.org/uc/item/7kc3 98r4.

11. Schell SF, Luke DA, Schooley MW, et al. Public health program capacity for sustainability: a new framework. Implement Sci. 2013;8(1):15. 